\title{
Estudo da microflora do megaesôfago chagásico
}

\author{
Microflora in chagasic megaesophagus

\begin{abstract}
Eduardo Crema'1, Andréa Berdu Madureira², Vanessa Guimarães de Freitas Lima², Ana Márcia
\end{abstract} \\ Werneck de Castro $^{2}$, Alex Augusto Silva ${ }^{1}$ e Iracema Saldanha Junqueira ${ }^{3}$
}

\begin{abstract}
Resumo Pacientes portadores de megaesôfago chagásico foram submetidos à endoscopia digestiva alta e coleta do material com pinças e sondas especiais, em condições estéreis. Foram realizadas quatro coletas, sendo uma do líquido de estase e três fragmentos da mucosa esofagiana respectivamente a um, três e cinco centímetros da transição esôfago-gástrica (linha Z). O material foi enviado em meio de cultura aos laboratórios de microbiologia e de anatomia patológica para a identificação dos germes presentes. Posteriormente, os resultados foram correlacionados ao grau de evolução do megaesôfago segundo a classificação de FerreiraSantos. Observou-se que é alta a incidência de germes patogênicos no megasôfago, independentemente do grau de dilatação, transformando a cirurgia para o tratamento desta afecção em potencialmente contaminada. Não houve diferença significativa quanto à positividade das culturas em relação ao grau de dilatação esofágica.
\end{abstract}

Palavras-chaves: Doença de Chagas. Megaesôfago. Microflora.

Abstract Chagasic patients with megaesophagus were submitted to an endoscopy of the upper digestive tract and the samples were collected with special instruments under sterilized conditions. One of the four samples collected was from the stase liquid and the other three samples were collected from fragments of the esophageal mucosa at one, three and five centimeters from the esophageal-stomach transition (Z line). The samples were analized by the Microbiology and Pathologic labs for the identification of microorganisms. After that, the results were correlated with the degree of mega esophagus according to Ferreira-Santos. We observed that the incidence of pathogenic microorganism is very high in megaesophagus, with no relation with the degree of dilatation making the surgery for the treatment of this afection potencially contaminated. There was no significant difference concerning the positivity of the culture relating to the degree of esophagus dilatation.

Key-words: Chagas' disease. Megaesophagus. Microflora.

A doença de Chagas é muito freqüente no Brasil acometendo 5 a 8 milhões de indivíduos ${ }^{24}$, principalmente no interior do país onde existem áreas endêmicas da moléstia. Acomete, geralmente, adultos jovens com maior incidência no sexo masculino. O predomínio de casos avançados no momento do diagnóstico torna o megaesôfago um sério problema de saúde pública.

O portador de megaesôfago apresenta estase alimentar crônica devido ao obstáculo funcional conseqüente à acalásia do cárdia, o que, somado à desnutrição presente na maioria destes pacientes, favorece a proliferação bacteriana na luz do esôfago. Sabe-se que esses indivíduos apresentam pneumonia de repetição, além de maior incidência de complicações infecciosas pós-operatórias, principalmente, pulmonares, mediastinais e da ferida cirúrgica.
Apesar de existirem poucas referências na literatura a respeito da flora normal do esôfago, destaca-se o estudo publicado por Trabulsi ${ }^{6}$ que considera o órgão estéril. Gagliardi ${ }^{3}$, estudando a flora bacteriana de indivíduos sem esofagopatia, encontrou uma flora esofagiana transitória e semelhante à da orofaringe. Bermudez et $\mathrm{al}^{1}$, ao estudarem doentes com tumor de esôfago, observaram que os microorganismos mais isolados foram a Cândida albicans (33,3\%), Peptostrepcoccus e Bacteroides melanogenicos $(22,2 \%)$, enterobactérias e Pseudomonas aeruginosa (11,1\%).

Devido ao fato do Triângulo Mineiro ser uma área de alta prevalência de indivíduos infectados pelo T. cruzi e por não encontrarmos publicações na literatura sobre a flora do esôfago no portador de megaesôfago, propusemo-nos a este estudo.

1. Disciplina de Cirurgia do Aparelho Digestivo da Faculdade de Medicina do Triângulo Mineiro (FMTM). 2. Acadêmicas do Curso de Medicina da Faculdade de Medicina do Triângulo Mineiro. 3. Serviço de Endoscopia da Faculdade de Medicina do Triângulo Mineiro, Uberaba, MG.

Endereço para correspondência: Dr. Eduardo Crema. Disciplina de Cirurgia do Aparelho Digestivo/FMTM. R. Getúlio Guaritá s/n. 38025-450 Uberaba, MG. Recebido para publicação em 17/05/01. 


\section{MATERIAL E MÉTODOS}

Foram estudados prospectivamente 44 pacientes portadores de megaesôfago, com duas sorologias positivas para doença de Chagas, tratados cirurgicamente no Serviço de Cirurgia do Aparelho Digestivo do Hospital Escola da Faculdade de Medicina do Triângulo Mineiro, após aprovação do Comitê de Ética local, sendo $32(72,7 \%)$ pacientes do sexo masculino e $12(27,3 \%)$ do sexo feminino. A faixa etária média foi de 57,9 anos (30-71 anos). Esses pacientes, após serem informados a respeito dos procedimentos a serem realizados, foram submetidos a endoscopia digestiva alta, em condições estéreis, sem preparo prévio do esôfago ou uso de antibióticos.

Foram realizadas quatro coletas, sendo uma do líquido de estase, quando presente (31 culturas), e três fragmentos de biópsias da mucosa esofagiana, respectivamente, a 1,3 e $5 \mathrm{~cm}$ da transição esofagogástrica (linha Z) em todos os pacientes, totalizando 163 culturas. As amostras foram colocadas nos meios de cultura ágar sangue, coagulase, novabiocina, manitol, tiogricolato, MacConkey, Sabouraud e de identificação em bateria que permitiram a identificação de germes gram positivo, gram negativo e leveduras. $O$ estudo foi realizado pelos laboratórios de microbiologia e de anatomia patológica desta faculdade.

Os pacientes foram então submetidos ao exame contrastado do esôfago, estômago e duodeno para classificação em graus segundo Ferreira-Santos ${ }^{5}$. Em seguida, correlacionaram-se os resultados das culturas com a classificação radiológica.

\section{RESULTADOS}

Do total das 163 amostras estudadas, notou-se positividade em $149(91,4 \%)$. Os germes mais freqüentemente encontrados foram Escherichia coli em $42(25,8 \%)$ culturas realizadas; Streptococcus species 27 (16,6\%); leveduras 26 (15,9\%); Klebsiella pneumoniae 23 (14,1\%)(Figura 1).

Das 31 culturas realizadas no líquido de estase, houve positividade em $100 \%$ das amostras.

Com relação às culturas realizadas nos fragmentos de mucosa esofagiana (132 culturas), encontrou-se positividade em $118(89,4 \%)$, distribuídos quanto ao local da biópsia em 39 (88,6\%), 38 (86,4\%), 41 (93,2\%), respectivamente, para as biópsias realizadas a 1, 3 e $5 \mathrm{~cm}$ da junção esôfago gástrica (Figura 2).

Quanto à associação do grau de dilatação esofágica e positividade da cultura, observamos: grau II $68(95,8 \%)$; grau III 45 (88,2\%); grau IV 37 (90,2\%) (Figura 3).

Quanto à distribuição dos germes nos diferentes graus de dilatação esofágica, encontramos:

Grau II: Klebsiella pneumoniae (22,5\%), Streptococcus sp (15,5\%) e Enterobacter cloacae $(15,5 \%)$;

Grau III: leveduras (29,4\%), E. coli (23,5\%), Klebsiella pneumoniae (13,7\%) e Streptococcus sp (13,7\%);

Grau IV: Escherichia coli (37\%), Streptococcus sp $(21,9 \%)$ e Staphylococcus coagulase negativa $(12,2 \%)$.

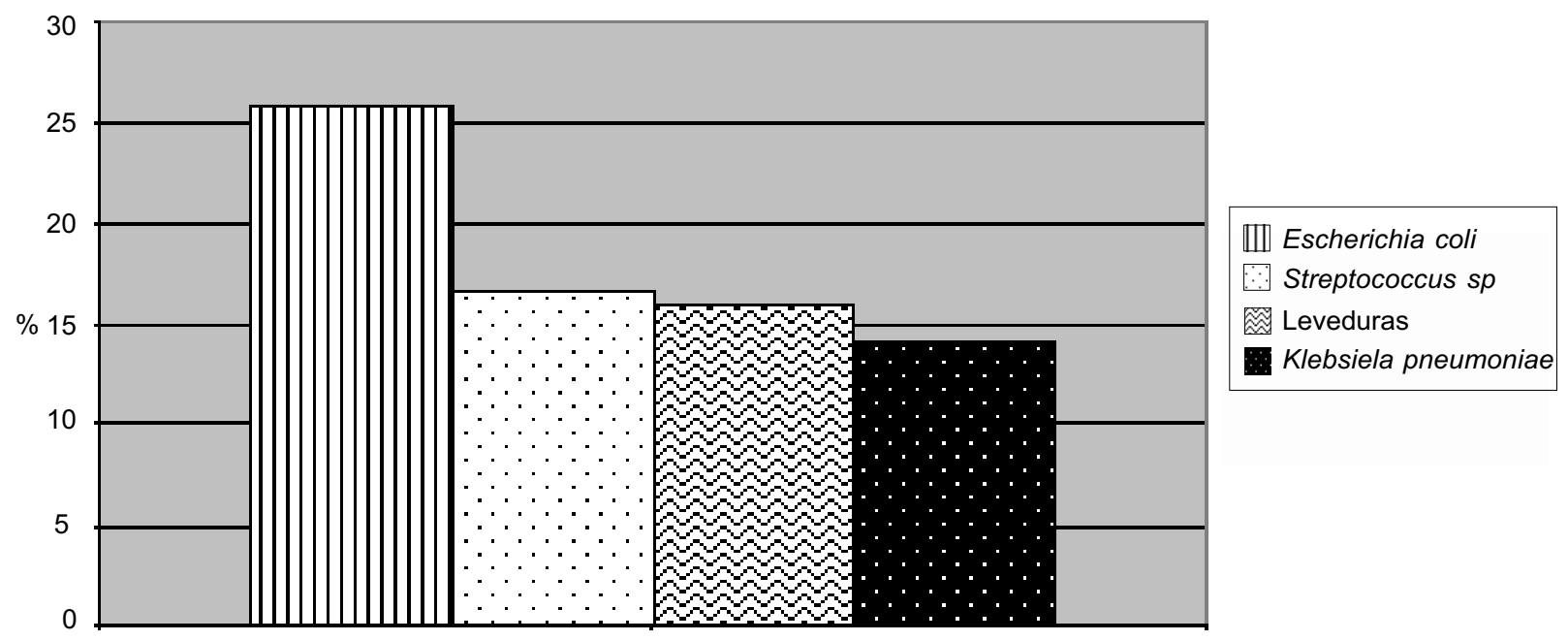

Figura 1 - Germes mais freqüentemente encontrados no megaesôfago chagásico e os respectivos percentuais de positividade. 


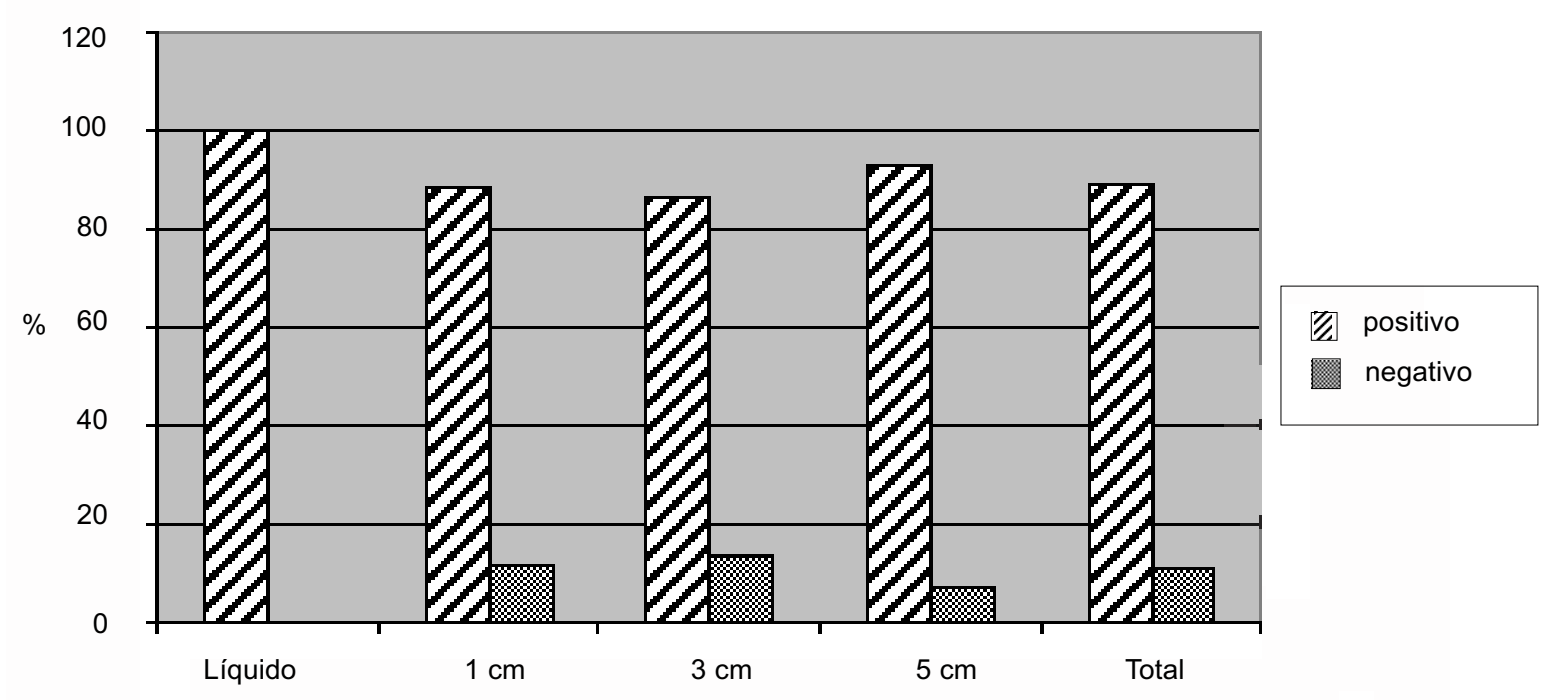

Figura 2 - Percentuais de positividade de cultura nos respectivos locais de coleta do material.

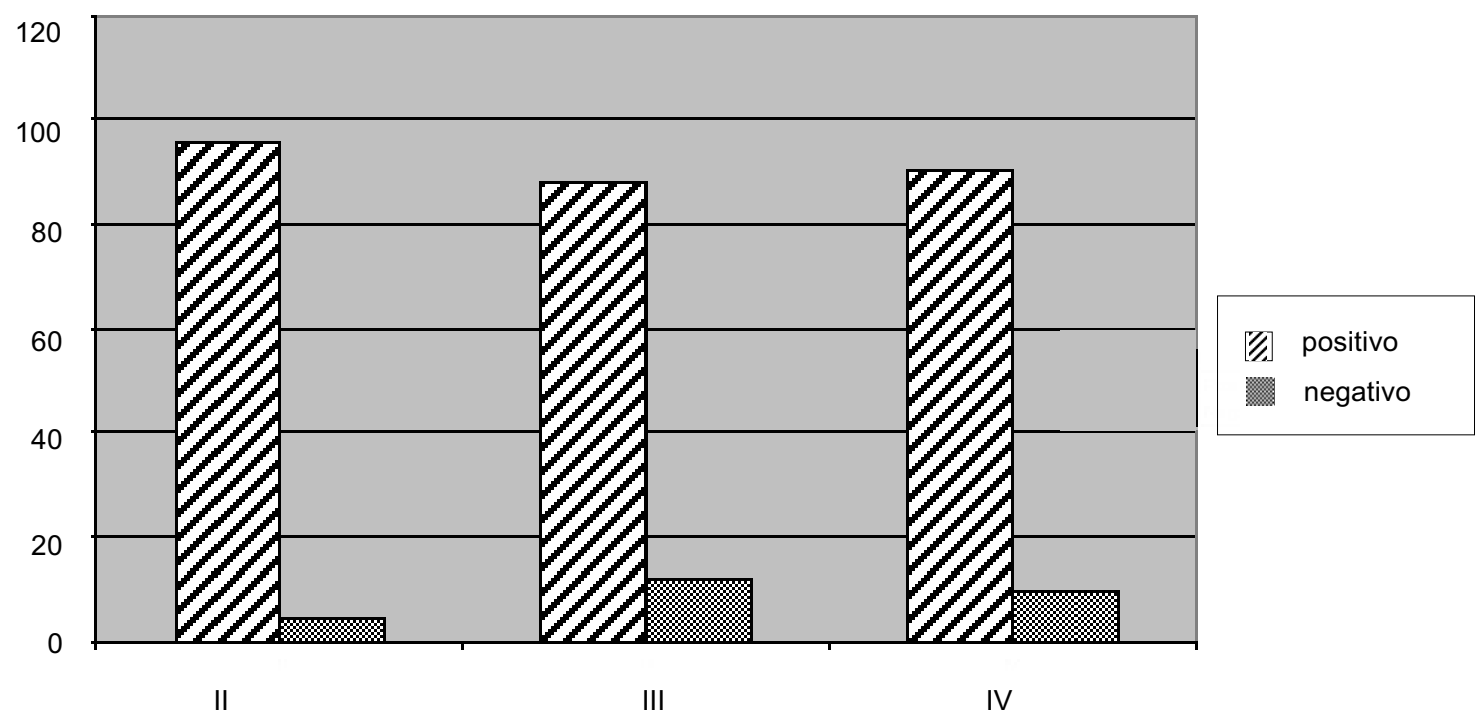

Figura 3 - Percentuais de positividade de microorganismos segundo o grau de dilatação do megaesôfago.

\section{DISCUSSÃO}

O esôfago normal, segundo Trabulsi ${ }^{6}$, seria estéril. Gagliardi $^{3}$ observou que a flora esofágica normal é transitória e semelhante a da orofaringe. Neste estudo, observamos o crescimento de germes patogênicos na mucosa do esôfago que apresentava dilatação e estase alimentar. Notou-se que os germes encontrados no líquido de estase e ou nos fragmentos de biópsia em portadores de megaesôfago chagásico são semelhantes aos encontrados na flora intestinal.
Bermudez ${ }^{1}$, ao analisar portadores de neoplasia esofágica, constatou acentuada predominância de fungos e anaeróbios sobre os aeróbios gram negativos e sugeriu como provável fonte a boca. Neste material, observou-se a presença de leveduras em $15,9 \%$ das culturas.

Houve $100 \%$ de positividade nas culturas realizadas no líquido de estase e $89,4 \%$ de positividade nas culturas feitas com os fragmentos 
de mucosa esofagiana, o que corrobora com a teoria de que a cirurgia de megaesôfago chagásico seja potencialmente contaminada. A comparação da positividade das culturas em relação aos graus de dilatação do esôfago não demonstra diferença significante quanto ao crescimento bacteriano.
Com base nestes resultados podemos concluir que é alta a incidência de germes patogênicos no megaesôfago chagásico. A partir da interpretação destes dados, devese considerar a cirurgia de megaesôfago como potencialmente contaminada, necessitando de preparo mecânico e antibioticoterapia profilática em todos os casos.

\section{REFERÊNCIAS BIBLIOGRÁFICAS}

1. Bermudez LE, Almeida J, Panza M, Vidal E. Estudo da microflora do esôfago e estômago em doentes com tumores gástricos esofageanos. Revista Brasileira de Cancerologia 4: 51-53, 1984.

2. Ferreira MS, Lopes ER, Chapadeiro E, Dias JCP, Ostermayer AL. Doença de Chagas. In: Veronesi R, Focaccia R (eds) Tratado de Infectologia, $4^{a}$ edição, Atheneu, São Paulo, vol. 2, p. 11751211, 1999.

3. Gagliardi D, Makihara S, Corsi PR, Biana AT, Wiczer MV, Nakakubo S, Mimica LM. Microbial flora of the normal esophagus. Diseases Esophagus 4: 248-250, 1998.
4. Lana M, Tafuri WL. Trypanosoma cruzi e Doença de Chagas. In: Neves DP, Melo AL, Genaro O, Linardi PM (eds) Parasitologia Humana, 9a edição, Atheneu, São Paulo, p. 82-114, 1997.

5. Santos RF. Tratamento Cirúrgico da Aperistalse Esofágica (megaesôfago). Tese para concurso de Professor Catedrático. Faculdade de Medicina de Ribeirão Preto. Universidade de São Paulo, Ribeirão Preto, SP, 1962.

6. Trabulsi LR, Toledo MRF. Flora Normal do Corpo Humano. In: Trabulsi LR (ed) Microbiologia, $2^{\mathrm{a}}$ edição, Atheneu, Rio de Janeiro, p. 44, 1996. 